\title{
BMJ Open Psychiatry peer review groups in Australia: a mixed-methods exploration of structure and function
}

\author{
Jeanette Lancaster, ${ }^{1}$ Shirley Prager, ${ }^{1}$ Louise Nash, ${ }^{2,3}$ Aspasia Karageorge (i) ${ }^{2}$
}

To cite: Lancaster J, Prager S, Nash L, et al. Psychiatry peer review groups in Australia: a mixed-methods exploration of structure and function. BMJ Open 2020;10:e040039. doi:10.1136/ bmjopen-2020-040039

- Prepublication history for this paper is available online. To view these files, please visit the journal online (http://dx.doi org/10.1136/bmjopen-2020040039).

Received 03 May 2020 Revised 14 August 2020 Accepted 30 September 2020

Check for updates

(C) Author(s) (or their employer(s)) 2020. Re-use permitted under CC BY-NC. No commercial re-use. See rights and permissions. Published by BMJ.

${ }^{1}$ Consultant Psychiatrist, Melbourne, Victoria, Australia ${ }^{2}$ Brain and Mind Centre, The University of Sydney, Sydney, New South Wales, Australia ${ }^{3}$ Headspace Early Intervention Team, Sydney Local Health District, Camperdown, New South Wales, Australia

Correspondence to Dr Aspasia Karageorge; aspasia.karageorge@sydney. edu.au

\section{ABSTRACT}

Objectives The purpose of this study was to examine Australian psychiatrists' experience of participation in a small group learning format of continuing professional development, known as peer review groups (PRGs), with a particular emphasis on group structure and functions.

Method An exploratory mixed-methods study comprising a survey $(n=77)$ and semistructured interviews $(n=6)$ with Australian psychiatrists participating in a PRG in the previous 12 months.

Results Qualitative findings indicate that PRGs address experiential learning through a focus on both breadth and specificity of work, as well as participants' experiences. Participants described using PRGs as a forum to manage difficult and complex work (through critiquing work, learning from one another, considering theory and guidelines, benchmarking, validating, reflecting and generalising learning) and to manage stress and well-being associated with crises, everyday stress and professional isolation. Particular structural aspects of PRGs considered essential to achieve these functions were selfselection of members, self-direction of meeting content and provision of a safe environment. These findings were convergent with the quantitative findings from scale survey data. Difficulties experienced during PRG participation are also described.

Conclusion Qualitative and quantitative findings from psychiatry PRGs demonstrate how practice-based professional experience functions as both a source of learning and of collegial connection that contributes to well-being and reduction in professional stress. Study limitations and future research directions are discussed.

\section{INTRODUCTION}

Most psychiatrists in Australia and New Zealand participate in a form of small group learning known as peer review groups (PRGs). These PRGs are voluntary yet registered with the Royal Australian and New Zealand College of Psychiatrists' (RANZCP) continuing professional development (CPD) programme. They are a popular form of CPD activity ${ }^{1}$ with $98 \%$ of Fellows of the RANZCP registered as participating in one or more of 1251 PRGs in 2020 across Australia, New Zealand and beyond (A Hill, RANZCP, personal communication 2020).

\section{Strengths and limitations of this study}

This research addresses experiential learning of practice, which is rarely addressed in the medical education literature.

- The study design includes questions addressing the impact of peer review groups on participants' professional and personal stress and well-being, an often-overlooked area of research into learning in continuing professional development.

- The inclusion of qualitative methods allows for an exploratory, rich description of participant experiences.

- A non-probability sampling method was used, therefore results may not be representative of the broader cohort of Australian psychiatrists, however, this sampling method suits the exploratory aims of the study and will allow for development of a more comprehensive cross-sectional survey in the future.

The RANZCP defines PRGs as 'small, selfselected groups of peers who meet to review their work in a setting that is organised to be supportive for individuals involved to present and learn from the presentation of work experiences and issues' (p13). ${ }^{2}$ Various forms of small groups are widely used in teaching and training in medicine, but their use in medical CPD, while possibly as common, is significantly under-researched. ${ }^{1}$ Small group learning based on groups of peers has been used in CPD in central and northern Continental Europe since the early 1970s (where such groups are known as Quality Circles) and later in Canada, Scotland and Ireland and the UK. They are used most commonly in primary care, but also in psychiatry in Europe, Australia and New Zealand. ${ }^{13}$ In Australia, PRGs were first set up in 1992, then evaluated soon after. ${ }^{45}$ Other jurisdictions and disciplines have used the RANZCP PRG format, such as the College of Psychiatrists of Ireland ${ }^{6}$ and the Australian and New Zealand College of Anaesthetists. ${ }^{7}$ However, there has been no further evaluation of their functioning in the literature. However, there is a growing awareness in the medical CPD 
literature of associations between learning and a range of factors, including a basis in clinical practice, interaction with peers and doctors' self-identified learning needs. ${ }^{8-10}$ It is also known that participation in small group learning fosters reflection on ethical and professional aspects of practice $^{811}$ and provides collegial support, especially for professional difficulties. ${ }^{11-13}$

After 25 years and thousands of PRGs, it is time to re-evaluate the functions of the RANZCP model of PRGs. The aim of this research is to explore psychiatrists' experiences of PRGs to understand their value to participants. The specific research questions are (1) what form of learning does PRGs address, (2) what are participant perceptions of the functions of PRGs and (3) what are participant perceptions of the structure of PRGs that support their function.

\section{METHOD}

\section{Design}

An exploratory mixed-methods study comprising a survey and semistructured interviews with PRG participants was undertaken. Responses to the survey questions were either descriptive, Likert-scaled or free-text responses to open-ended questions. Quantitative analysis of the scale survey data was undertaken to capture the structure of PRGs, how frequently/commonly particular functions were considered important to respondents' participation in PRGs. Qualitative analysis of free-text responses and interview transcripts was undertaken to identify and expand on themes of PRG experience that had not yet been considered. This qualitative component was considered essential to the exploratory nature of the study aim. ${ }^{14}$

\section{Participants}

A non-probability sample of 77 psychiatrists completed the online survey, and 8 psychiatrists participated in an interview. Participants were psychiatrists working in Australia who had participated in a PRG in Australia in the previous 12 months.

\section{Patient and public involvement}

No patients were involved in this research.

\section{Procedure}

Survey development

A survey was developed guided by an extensive literature review $^{1}$ and consideration of the questions used in the 1990s survey. ${ }^{4}$ The survey comprised descriptive questions, Likert scales and free-text responses to open-ended questions. At the end of the survey, participants were invited to contact the research team if they were interested in an interview about their PRG experiences. The survey design was piloted for readability and length with two PRGs ( $\mathrm{n}=14$ people) in September 2018 with minor changes made as a result.

\section{Recruitment and data collection}

We used both purposive and snowball sampling procedures to recruit participants for this study. First, during a presentation about this project at the RANZCP Congress in May 2018, and at the World Asian Psychiatrists Conference in Sydney in February 2019, psychiatrists were invited to provide contact details for recruitment into the study for survey and or interview. In order to ensure representation across all Australian states and territories, psychiatrists known by the research team from other states and territories were purposively emailed the invitation. A total of 86 psychiatrists expressed interest in the project for the survey and were emailed an online link using Survey Monkey. Next, a snowballing recruitment technique was then used in that these 86 psychiatrists were asked to forward the link on to other psychiatrists who they thought may be interested. Survey respondents were invited to contact the researchers should they wish to take part in an interview, with contact details provided to them at the completion of the survey. Interviews were conducted by phone or in person by one of the authors, $\mathrm{AK}$, who is not a psychiatrist and therefore not a member of the RANZCP. Interviews were $30 \mathrm{~min}$ in duration and followed a question schedule which closely followed the open-ended questions asked in the survey (ie, functions of PRGs, structure of PRGs, difficulties and benefits of participation) and were audio-recorded and then transcribed by a professional transcription company.

\section{Analytic procedure}

For quantitative data, simple descriptive statistics were used. For qualitative data, we followed Clarke and Braun's ${ }^{15} 16$ procedure for conducting an inductive thematic analysis on qualitative data. Free-text survey responses and deidentified interview transcripts were subjected to a recursive coding process by the authors to identify and interpret patterns of meaning across the data in relation to the research questions. After familiarising ourselves with the data, initial codes were generated, themes were developed and defined and finally, the coding framework was reviewed and refined in light of group discussion.

\section{FINDINGS}

\section{Description of sample}

A total of 77 psychiatrists completed the survey. Given the recruitment method used, the response rate to the email invitation to the survey is unknown. Survey participants were comprised of $60 \%$ men, working in differing combinations of private and public practice, with over half participating in multiple PRGs (see table 1). A total of six psychiatrists took part in a semistructured interview (50\% men), working across a variety of areas of psychiatry practice (community, psychotherapy, old age, academic, adult).

\section{PRG CHARACTERISTICS}

Survey participants were asked to describe the PRG in which they had participated for the longest on a series 
Table 1 Survey respondent characteristics $(n=77)$

$M(S D) \quad n(\%)$

\begin{tabular}{lc}
\hline $\begin{array}{l}\text { Demographics } \\
\text { Age (years) }\end{array}$ & \\
\hline Female & $31(40.3)$ \\
\hline Aboriginal or Torres Strait Islander & $1(1.3)$ \\
\hline $\begin{array}{l}\text { Professional role } \\
\text { Retired from psychiatry }\end{array}$ & $0(0.0)$ \\
\hline Private psychiatric practice only & $29(37.6)$ \\
\hline Public psychiatric practice only & $20(26.0)$ \\
\hline Combination of private and public & $28(36.4)$ \\
\hline Research and teaching involvement & \\
\hline Teaching and/or supervision role & $66(85.7)$ \\
\hline Undertakes research & $31(40.3)$ \\
Number of participating PRGs & \\
\hline One & $35(45.5)$ \\
\hline Two & $33(42.9)$ \\
\hline Three or more & $9(11.6)$ \\
\hline
\end{tabular}

PRGs, peer review groups.

of characteristics (see table 2). Groups predominantly met once per month $(78 \%)$ and face-to-face $(90 \%)$ in varying locations, such as workplaces $(36 \%)$ and restaurants $(25 \%)$. All states and territories in Australia were represented except Tasmania.

Benefits and functions of PRG participation: Likert scale items Almost all participants $(97.4 \%)$ rated their PRG as providing a safe space for reflection and peer support. Similarly, over three quarters rated their PRG participation as beneficial to well-being, stress reduction and clinical care (see table 3).

Table 4 outlines different areas to which PRG participation might be considered helpful by participants. Areas most frequently endorsed as very helpful were collegiality and connectivity $(88.3 \%)$, and help with complex cases (88.2\%; see table 4 for other areas).

\section{Qualitative findings}

We developed a set of themes for best describing the qualitative data in response to our specific research questions. Finally, we describe some of the difficulties and costs of PRG participation.

Category 1: form of learning addressed by PRGs Experiential learning

The form of learning that emerges from PRG participation differs from traditional curriculum or theoretical knowledge-based forms, in that PRG work is based on participants' experiences of their own practice. PRGs function as sites where the experiential aspects of professional knowledge are shared and processed.
Table 2 Characteristics of longest-attending PRG $(n=77)$

n (\%)

\begin{tabular}{|c|c|}
\hline \multicolumn{2}{|l|}{ Location type } \\
\hline Capital city & $65(84.4)$ \\
\hline Regional city & $6(7.8)$ \\
\hline Rural & $2(2.6)$ \\
\hline Mixed-video or telephone group & $4(5.2)$ \\
\hline \multicolumn{2}{|l|}{ State or territory } \\
\hline New South Wales & $36(46.8)$ \\
\hline Victoria & $23(29.9)$ \\
\hline Queensland & $5(6.5)$ \\
\hline Australian Capital Territory & $4(5.2)$ \\
\hline South Australia & $4(5.2)$ \\
\hline Western Australia & $3(3.9)$ \\
\hline Northern Territory & $2(2.6)$ \\
\hline Tasmania & $0(0.0)$ \\
\hline \multicolumn{2}{|l|}{ Meeting format } \\
\hline Face to face & $72(94.7)$ \\
\hline Video or teleconferencing & $5(6.5)$ \\
\hline \multicolumn{2}{|l|}{ Meeting location } \\
\hline Public hospital facility & $10(13.2)$ \\
\hline Private hospital facility & $5(6.6)$ \\
\hline Private practice & $13(17.1)$ \\
\hline Restaurant & $19(25.0)$ \\
\hline Private home & $16(21.1)$ \\
\hline Other & $13(17.1)$ \\
\hline \multicolumn{2}{|l|}{ Meeting frequency } \\
\hline Weekly & $4(5.2)$ \\
\hline Fortnightly & $10(12.9)$ \\
\hline Monthly & $60(77.9)$ \\
\hline Less than monthly & $3(4.0)$ \\
\hline \multicolumn{2}{|l|}{ Meeting duration } \\
\hline 1 hour & $7(9.1)$ \\
\hline 1.5 hours & $40(51.9)$ \\
\hline 2 hours & $15(19.5)$ \\
\hline 3 hours & $13(16.9)$ \\
\hline Other & $2(2.6)$ \\
\hline
\end{tabular}

All, or mostly all, participants from

\begin{tabular}{lc} 
Adult psychiatry & $20(26.0)$ \\
\hline Psychotherapy & $13(16.9)$ \\
\hline General psychiatry & $13(16.9)$ \\
\hline Psychoanalysis & $8(10.4)$ \\
Child and adolescent psychiatry & $5(6.5)$ \\
Forensic psychiatry & $5(6.5)$ \\
\hline Other $^{\star}$ & $13(16.9)$ \\
\hline
\end{tabular}

${ }^{*}$ Other included administration, old age psychiatry, youth mental health and mixed-discipline groups.

PRG, peer review group. 
Table 3 Peer review group benefits and functions $(n=77)$; n (\%)

\begin{tabular}{|c|c|c|c|}
\hline & Yes & No & Unsure \\
\hline \multicolumn{4}{|l|}{ Does participation in a PRG } \\
\hline $\begin{array}{l}\text { Reduce your workplace } \\
\text { stress }\end{array}$ & $62(80.5)$ & $8(10.4)$ & $7(9.1)$ \\
\hline Enhance your well-being & $61(79.2)$ & $9(11.7)$ & $7(9.1)$ \\
\hline $\begin{array}{l}\text { Provide benefit to your } \\
\text { doctor-patient relationships }\end{array}$ & $66(85.7)$ & $4(5.2)$ & $7(9.1)$ \\
\hline \multicolumn{4}{|c|}{ Does PRG participation allow you a safe space to } \\
\hline Reflect on your own practice & $74(97.4)$ & $2(2.6)$ & $0(0.0)$ \\
\hline $\begin{array}{l}\text { Compare your practice to } \\
\text { that of others }\end{array}$ & $72(93.5)$ & $3(3.9)$ & $1(1.3)$ \\
\hline Ask for help from your peers & $74(97.4)$ & $1(1.3)$ & $1(1.3)$ \\
\hline
\end{tabular}

PRG, peer review group.

It is real-life experience that shapes the opinions of your peers (many years of real life experience). You cannot get that in the same way from a text or a journal or a conference.

Enables learning from experience. Time to reflect on matters relevant in the present. Learning from the most difficult situations. Time to work at depth.

\section{Breadth of work}

Because PRGs address the experiences of psychiatric practice, review of the breadth of psychiatrists' work is possible.

Nowhere else is as conducive to discussing the problems of being a psychiatrist. I can get case discussions elsewhere but not the issues about a working life.

In private practice this is the only opportunity to get a broad view of clinical ideas and management approaches regarding specific cases from my peers.

\section{Specificity of work}

Using participants' experiential material allows for specific cases or situations to be considered. This gives depth, to an understanding of the patient or situation, and to what management or options are needed and possible. While PRG work most commonly involves clinical cases, it may also include related contextual, systemic and organisational issues. Consideration of these gives clinical work the specificity and depth that underpins patient-centred care.

Often system, ethical and clinical issues impact on a particular case.

We are able to have a more patient-centred care when discussing individual cases.

\section{Focus on participants' experience}

Participants' immediate needs were described as the focus of PRG work, which gives a sense of timeliness and a real-life quality to the group work, reflecting participants' engagement in a process that is meaningful to them.

Up close and personal discussion of case material.

Conversations are deeper, more personal and more acknowledging of one's actual feelings.

It is real and live.

\section{Category 2: perceived functions of PRGs Managing difficult and complex work}

Participants reported using their PRGs for getting help with both work that is difficult, complex or that presents dilemmas, and with everyday work that cannot be standardised, where the judgement that constitutes the 'know-how' of psychiatric work is needed.

Some of the most helpful PRG sessions have been when I have felt in most difficulty about how to understand the clinical situation.

[A] safe space to discuss complex cases and adverse events.

Table 4 Functions of peer review group participation $(n=77) ; n(\%)$

\begin{tabular}{|c|c|c|c|}
\hline How helpful is PRG participation to you in the following areas: & Not at all helpful & Somewhat helpful & Very helpful \\
\hline To receive help with complex cases & $0(0.0)$ & $9(11.8)$ & $67(88.2)$ \\
\hline Ethical issues & $2(2.6)$ & $12(15.6)$ & $63(81.8)$ \\
\hline To receive constructive critique from peers & $2(2.6)$ & $12(15.8)$ & $62(81.6)$ \\
\hline To share ideas and methods & $1(1.3)$ & $17(22.4)$ & $58(76.3)$ \\
\hline A source of professional identity & $7(9.1)$ & $22(28.6)$ & $48(62.3)$ \\
\hline Individual knowledge and skills & $3(3.9)$ & $33(42.9)$ & $41(53.2)$ \\
\hline
\end{tabular}

$\mathrm{n}$ for each row varies from 76 to 77 due to missing data. Percentages are adjusted accordingly.

PRG, peer review group. 
Participants described getting help and using their PRGs in a variety of ways:

\section{Critiquing work}

Participants described using the range of differing perspectives available in their group to have their work critiqued, and to discover alternative approaches to problems and issues:

The opportunity to get feedback on one's way of doing things from other respected colleagues who may see things and do things differently.

The ability to review and reflect on my practice and learn from others.

\section{Learning from others}

Participants work collaboratively, sharing experiences. They provide information, resources and give advice to one another.

There are members who will share something new, something which has been recently published or something which helps you improve your practice or revisit your own practice.

Real-time professional colleagues' advice.

\section{The use of theory and guidelines}

Participants review those aspects of work that cannot be standardised, for example, how theory and guidelines may be interpreted, and what does and does not work, in practice.

how to temper clinical guidelines, research base and clinical experience.

robust discussion based on clinical experience as well as clinical implementation of theory/evidence.

\section{Considering the boundaries of current practice}

PRGs are a site where participants explore how guidelines can be extended and adapted for newly emerging circumstances.

In many ways I am quality controlling treatment beyond the guidelines and making sure others agree with the approach.

checking in [on] how colleagues are reviewing the evidence and carefully adding thinking, techniques or modalities to management plans or actual practice is very helpful.

\section{Benchmarking and validation}

PRG participants compare their own work with that of their peers.

Affirmation that my practice is within peer-accepted norms.

Sharing experiences about one's practice and finding out where they fit into the normal distribution curve of other people's practice.
Reflection

Because this is group work, the interactive function of group processes allows participants to use the group for reflective and integrative purposes.

One of the crucial things is having a forum for thinking about what could have been missed, what could be understood differently, what other ways there might be of managing an issue or seeing issues in a new way.

Sometimes the group has provided a collective insight that has shifted an impasse, and sometimes [it] was simply a space that helped me process the relationship to come up with a new position myself.

\section{Generalisation of learning}

The reflective aspects of group functioning may also serve as a model for participants' own work, and be generalised to other work contexts.

The deep and integrative listening and thinking and feeling is modelled in my group and demonstrates what is needed in practice.

Presenting cases leads to better understanding of transference/counter-transference and enhances the relationship to the individual discussed and then can generalize to other patients.

\section{Relations}

Group processes also allow relational aspects of practice to be considered, most significantly the doctor-patient relationship.

Each issue is slightly different and the interaction between oneself and the patient is always complex and contributed to by both the psychiatrist and patient.

Sometimes [PRG participation] has simply helped me survive problematic doctor-patient relationships, as sadly not everything is resolvable.

\section{Managing stress and well-being}

Participants use the groups to manage factors that potentially impact negatively on their well-being: crises, everyday stresses of the work and the need to reduce professional isolation.

\section{Crises}

Participants described using PRGs for support in debriefing and managing crises:

Sharing the crisis is the most potent form of reduction of panic.

[support for] situations of high stress, for example, patient suicide/coronial cases; distressing cases and workplace issues.

Safety valve, source of grounding, direct personal support with untoward events.

\section{Everyday stress}

Groups also support management for the ongoing uncertainties in psychiatric work: 
The PRG can also facilitate better tolerance of difficult clinical situations that call for patience and tolerance of difficulty.

[PRG participation] makes me a better doctor - more balanced, less stressed.

\section{Mitigating professional isolation}

Participants are aware that psychiatric practice can be isolating in many different ways including geographic isolation; the responsibility of a specific role; subspecialisation or the inherent nature of dyadic work.

Psychiatric practice can be isolating and PRGs provide an invaluable way to make and sustain deep professional connections over time.

\section{Category 3: structure of PRGs}

Particular aspects of the PRG structure are central to their functioning. These are self-selection of membership, self-direction of the work and a sense of safety for participants.

\section{Self-selection}

Self-selection of the composition of the group allows participants to choose colleagues who work similarly. However, participants also described the importance of diversity in the context of learning, so the needs for compatibility and diversity of perspectives have to be balanced.

Our group found [self-selection] helpful to create a balance of people who have useful opinions and perspectives.

There needs to be sufficient like-mindedness to make it work, but also the ability to supportively confront.

\section{Self-direction}

As participants direct the content of the PRG meeting, the work undertaken is timely and relevant. This selfdirection is experienced as freeing and flexible:

[Self-direction] enables a more spontaneous and relevant exploration and discussion of issues that have arisen naturally from the group members work. More relevant and helpful.

It allows current issues of importance to one or more members to be discussed as they arise. The flexibility is vital.

\section{Safety}

Participants described needing to be able to trust the group as a safe, non-judgemental and confidential place. Trust allows participants to reveal the vulnerability of knowledge gaps and errors:

It is highly important to feel comfortable within a PRG with like-minded peers to discuss anything of relevance without having any fear of being judged, humiliated or subjected to any form of unwanted repercussions.
A safe place to show my ignorance/confusion/ uncertainty.

Such openness was described as necessary to facilitate feedback and constructive criticism:

[The PRG] is a place where personal exposure can be done safely and the issues affecting both the therapist and patient can be explored.

You need both trust and candour for best PRG functioning.

\section{Category 4: difficulties}

Participants in PRGs were asked to described difficulties they experience in the group functioning. Although difficulties were not commonly reported, these included interpersonal difficulties, limited or no benefit from participation or particular costs of attendance.

\section{Interpersonal difficulties}

Some participants described tensions between group members, such as dominance of one group member.

One difficult issue to do with one member advocating a new member which the rest of the group felt wasn't suitable because of confidential issues.

\section{PRGs not helpful}

Some participants experienced their PRGs as being of limited or no help because of the nature of their practice, inaccessibility of genuine peers or lack of fit in a PRG. Some found that their learning needs were met elsewhere.

Very little to learn that is not learnt as part of a large psychiatry department.

\section{Costs}

The most common costs described were that PRG attendance is time-expensive involving the loss of personal or family time, practice or travel time.

Personal time is the greatest cost, away from my young family, travelling.

Time [is a cost], but it's worth every minute!

Specific difficulties were described in relation to some PRGs based in service organisations where self-selection was over-ridden by organisational demands.

\section{Power differential}

Some workplace-based PRGs are hierarchical in nature. As compared with a flat hierarchy of peers, this power differential can subtly limit the freedom to speak openly.

At first, being open about things that weren't working was quite difficult $[\ldots]$ occasionally you think, oh do I want him to know about this?

\section{Shift of group purpose}

In other workplace-based groups, participants described the group session being used for discussion of 
organisational issues related to the workplace, rather than their own individual work needs.

[a senior] psychiatrist is part of the group and sometimes we [talk] about service issues.

\section{DISCUSSION}

The origin of this research was to understand why Australian psychiatrists choose to participate in PRGs, a unique form of CPD. Through administration of a mixed-methods survey and semistructured interviews, we explored psychiatrists' perspectives on how and why they use these groups, the form of learning PRGs are based on, the groups' structure and their function. Principal findings include that PRG learning is experiential, meaningful, engaging and different to other CPD options; that some CPD processes are better managed by practitioners in a group, rather than individually and the importance of collegial support to the practice of medicine and practitioner well-being.

Given the dearth of research on PRGs as a form of CPD, the use of qualitative methods was a particular strength to the study design given it's exploratory and hypothesisgenerating nature. However, there are limitations to the findings. First, we used purposive and snowball sampling strategies and, as such, the sample is not randomly selected and nor do we know the response rate. However, this is not of particular importance for assessing the rigour of a thematic analysis of qualitative data ${ }^{14}{ }^{17}$ but should be taken into consideration regarding the generalisability of Likert scale survey findings. A higher proportion of psychiatrists involved in teaching and research were also represented by the sample than would be expected in a random cross-section of PRG participants, and this is likely a result of the sampling procedures used. Second, both survey and interview data were self-report and there are known limitations to such methods ${ }^{18} 19$ although the self-report design was in line with the study aim to explore participant experiences. There were very few outcomes of interest which could have been objectively measured. Finally, it should be mentioned that participants were asked to reflect on their experience of their longest-serving PRG when responding to Likert scale questions. It is very likely that these findings represent the best of PRG experiences, given that people are more likely to remain in a group for longer if the experience is providing benefit to them. On the other hand, participants reflected on all current and previous experiences of PRG participation when responding to qualitative questions, in both the survey and interview.

Although there is a paucity of studies examining PRGs specifically, our findings can be considered in terms of the wider medical CPD literature. First, the small group learning formats most commonly used in medical CPD are those developed by professional organisations with the aim of implementing updated knowledge in doctors' practice, in order to improve professional performance and clinical outcomes. ${ }^{20}$ These groups are curriculum driven with a focus on formal topics, using teaching materials such as modules or guidelines, and are commonly managed by a trained facilitator. ${ }^{13} 2021$ In contrast, our findings indicate that the RANZCP model of PRGs can be understood as being practice driven; PRG work is based on the participants' own practice material and selfexperienced needs. Thus, PRGs function as sites where experiential aspects of professional psychiatric knowledge are shared and processed.

Next, our findings indicate that the basic process of PRGs is a collaborative discussion for critiquing presented work and addressing problems, which has a range of outcomes. Participants in this study reported using PRGs for assistance in managing the uncertainty which is a pervasive feature of medical practice, ${ }^{22}{ }^{23}$ by gaining feedback from peers. Through debate about clinical dilemmas, ethical issues and scenarios beyond standard guidelines, participants also described using PRGs as a forum for the creation of new psychiatric knowledge. Participants compared their work with their colleagues, not in competition, but as evaluative judgement, the capability of judging the quality of one's own work in relation to the quality of others' work. ${ }^{24}$ This interactive approach to considering one's own work may allow participants to address relational issues and to reflect on, and integrate, their work, in ways not afforded by more common small group formats. Further, our findings highlight the importance of the psychosocial and affective aspects of PRG participation. Both quantitative and qualitative findings show that respondents use the collegial contact with peers to reduce professional isolation and to manage the stresses of work. This support is a significant function of PRGs at a time when COVID-19, medical suicide, vicarious trauma and burnout are significant matters of concern for the profession. ${ }^{25-28}$

Finally, the three structural aspects of PRGs that respondents felt were important all relate to the groups' boundaries and highlight the groups' reliance on the supporting organisation (ie, the RANZCP). These are the self-selection of group members, the self-direction of group work and the safety of presenting which is contributed to by the qualified privilege (All PRGs registered with the RANZCP are covered by qualified privilege in Australia. Qualified privilege protects the confidentiality of information that identifies individuals, that becomes known solely as a result of declared quality assurance activities and gives immunity from civil liability to people who carry out activities in good faith as part of the declared QAA) provided by the RANZCP for CPD activities (pp12, 29) ${ }^{29}$ Self-selection of members is a common feature of peer groups and quality circles worldwide. ${ }^{1}$ In contrast, self-direction of group work is uncommon elsewhere. Our findings indicate that selfdirection underpins the experience of participants that PRG work is personally relevant and meaningful, which is in turn associated with learning, ${ }^{81030}$ and is a protective factor in burnout. ${ }^{31} 32$ 
Further research in this area is needed to build on the current findings. The authors are currently engaged in a second phase of this project that incorporates a crosssectional survey of RANZCP NSW Branch participants about their experiences of PRGs. The aim of the second phase is to further develop and/or extend the themes identified in this paper, as well as provide greater methodological rigour through use of a more representative sample. This includes a more in-depth exploration of the potential relationship between group learning activities, such as PRGs, and practitioners' well-being. In terms of future practical applications, the RANZCP model of PRGs may be of value in the CPD programmes of other medical specialties, nursing and allied health professions. For that reason, the design of the second phase of this project also includes a consideration of how this model may benefit other medical specialties. Given the changes to medical practice due to COVID-19, with ongoing implications for collegiality and well-being, future research may also explore how the PRG format can be responsive to this.

To conclude, this study highlights the value that psychiatrists place in PRGs as a unique way of reviewing their practice experience most broadly, with all its clinical, cognitive, psychosocial, contextual, interactive and affective aspects. Our research suggests that PRGs both provide a particular form of group experiential learning which is rarely recognised as learning, and that participation may contribute to the reduction of vulnerability to stress and burnout.

Contributors All authors contributed to the design, data collection, data analysis and write-up of this paper. JL, SP, LN and AK collaboratively designed the research questions and methods of this study. Recruitment was conducted at two conferences; in the first instance by SP and AK for survey and interview participants (RANZCP Congress 2018 in Auckland, New Zealand), and in the second instance by LN and AK for interview participants (World Congress of Asian Psychiatrists 2019 in Sydney, Australia). Recruitment was also conducted through professional contact requests by SP, LN and JL. AK undertook participant interviews and survey collection activities. JL, SP and AK conducted the first round of qualitative analysis, and LN contributed to subsequent analysis. JL led the final round of qualitative data analysis and categorisation of themes. Quantitative analysis was largely undertaken by AK. Manuscript preparation was led by JL and AK, however, SP and LN contributed significantly to the content and formatting of the manuscript. The literature reviewed in the manuscript was largely conducted by $\mathrm{JL}$, with input by AK as it related to qualitative methods. The final version of the manuscript was checked by all four authors (JL, SP, LN and AK).

Funding This work was supported by two Avant Foundation grants awarded to A/ Prof Louise Nash in 2018 and 2019.

Competing interests None declared.

Patient and public involvement Patients and/or the public were not involved in the design, or conduct, or reporting, or dissemination plans of this research.

\section{Patient consent for publication Not required.}

Ethics approval Informed consent procedures were used and ethical approval provided by the Hunter New England Human Research Ethics Committee.

Provenance and peer review Not commissioned; externally peer reviewed.

Data availability statement Data are available upon reasonable request. Deidentified participant data may be requested from A/Prof Louise Nash at the University of Sydney by emailing louise.nash@sydney.edu.au.

Open access This is an open access article distributed in accordance with the Creative Commons Attribution Non Commercial (CC BY-NC 4.0) license, which permits others to distribute, remix, adapt, build upon this work non-commercially, and license their derivative works on different terms, provided the original work is properly cited, appropriate credit is given, any changes made indicated, and the use is non-commercial. See: http://creativecommons.org/licenses/by-nc/4.0/.

ORCID iD

Aspasia Karageorge http://orcid.org/0000-0002-7898-042X

\section{REFERENCES}

1 Karageorge A, Lancaster J, Prager S, et al. Where do peer review groups fit in the International continuing professional development literature? Australas Psychiatry 2019;27:651-4.

2 Royal Australia and New Zealand College of Psychiatrists. RANZCP continuing professional development program guide, 2019. Available: https://www.ranzcp.org/publications/ [Accessed Jan 2019].

3 Rohrbasser A, Harris J, Mickan S, et al. Quality circles for quality improvement in primary health care: their origins, spread, effectiveness and lacunae- a scoping review. PLoS One 2018;13:e0202616.

4 Balla M, Knothe B, Lancaster J, et al. Group peer review in psychiatry: the relationship to quality improvement and quality care. Aust N Z J Psychiatry 1996;30:653-9.

5 Beatson J, Rushford N, Halasz G, et al. Group peer review: a questionnaire-based survey. Aust N Z J Psychiatry 1996;30:643-52.

6 College of Psychiatrists of Ireland. Professional competence for psychiatrists: including CPD and clinical (practice) audit, 2019. Available: https://www.irishpsychiatry.ie/wp-content/uploads/2019/ 06/PCS-Handbook-17-April-2019-1.pdf, https://www.irishpsychiatry. ie/wp-content/uploads/2016/10/PCS-Handbook-MASTER-COPY-30. 06.17.pdf

7 Reilly J, Tay T. Peer review groups for continuing professional development in anaesthesia: the first two years of a peer review group program in Newcastle, Australia. Anaesthesia and Intensive Care 2017;45:114.

8 Mamede S, Loyens S, Ezequiel O, et al. Effects of reviewing routine practices on learning outcomes in continuing education. Med Educ 2013;47:701-10.

9 Kjaer NK, Halling A, Pedersen LB. General practitioners' preferences for future continuous professional development: evidence from a Danish discrete choice experiment. Educ Prim Care 2015;26:4-10.

10 VanNieuwenborg L, Goossens M, De Lepeleire J, et al. Continuing medical education for general practitioners: a practice format. Postgrad Med J 2016;92:217-22.

11 Gill D, Griffin A, Launer J. Fostering professionalism among doctors: the role of workplace discussion groups. Postgrad Med J 2014;90:565-70.

12 Abildsnes E, Flottorp S, Stensland P. Case stories in general practice: a focus group study. BMJ Open 2012;2:e001208.

13 Cunningham DE, Zlotos L. Ten years of practice-based small group learning (PBSGL) in Scotland - a survey of general practitioners. Educ Prim Care 2016;27:306-13.

14 Hammarberg K, Kirkman M, de Lacey S. Qualitative research methods: when to use them and how to judge them. Hum Reprod 2016;31:498-501.

15 Braun V, Clarke V. Using thematic analysis in psychology. Qual Res Psychol 2006;3:77-101.

16 Clarke V, Braun V. Thematic analysis. In: Michalos AC, ed. Encyclopaedia of quality of life and well-being research. Dordrecht, The Netherlands: Springer, 2014: 6626-8.

17 Sampling GG. Representativeness and Generalizability. In: Seale C, Core SRM, eds. Qualitative research practice. London, Thousand Oaks, CA: SAGE, 2004: 405-26.

18 Demetriou C, Ozer BU, Essau CA. Self-report questionnaires. Encyclopedia Clin Psychol 2014:1-6.

19 Chan D. So why ask me? Are self-report data really that bad? In: Lance CE, Vandenberg RJ, eds. Statistical and methodological myths and urban legends: doctrine, verity and Fable in the organizational and social sciences. New York: Routledge, 2009: 309-32.

20 Armson H, MacVicar R. The thistle and the maple leaf: practicebased small-group learning in Canada and ScotlandClinical Uncertainty in Primary Care, Springer, 2013: 117-46.

21 Zaher E, Ratnapalan S. Practice-Based small group learning programs: systematic review. Can Fam Physician 2012;58:637-42.

22 Sommers LS, Launer J. Clinical uncertainty in primary care: the challenge of collaborative engagement. Springer Science \& Business Media, 2013.

23 Simpkin AL, Schwartzstein RM. Tolerating uncertainty -the - medical revolution? N Engl J Med 2016;375:1713-5. 
24 Tai J, Ajjawi R, Boud D, et al. Developing evaluative judgement: enabling students to make decisions about the quality of work. High Educ 2018;76:467-81.

25 Maslach C, Leiter MP. Understanding the burnout experience: recent research and its implications for psychiatry. World Psychiatry 2016;15:103-11.

26 Baigent M, Baigent R. Burnout in the medical profession: not a rite of passage. Med J Aust 2018;208:471-2.

27 Axisa C, Nash L, Kelly P, et al. Psychiatric morbidity, burnout and distress in Australian physician trainees. Australian Health Rev 2019

28 Isobel S, Angus-Leppan G. Neuro-reciprocity and vicarious trauma in psychiatrists. Australas Psychiatry 2018;26:388-90.
29 Royal Australia and New Zealand College of Psychiatrists. 2020 RANZCP continuing Proefssional development program guide, 2020. Available: https://www.ranzcp.org/membership/cpd-program [Accessed May 2020]

30 Kjaer NK, Steenstrup AP, Pedersen LB, et al. Continuous professional development for GPs: experience from Denmark. Postgrad Med J 2014;90:383-7.

31 West CP, Dyrbye LN, Rabatin JT, et al. Intervention to promote physician well-being, job satisfaction, and professionalism: a randomized clinical trial. JAMA Intern Med 2014:174:527-33.

32 Shanafelt TD. Enhancing meaning in work: a prescription for preventing physician burnout and promoting patient-centered care. JAMA 2009;302:1338-40. 